\title{
Urban Fate and Transport Modeling of Contaminants: The Unique Needs of Emergency Response and the Potential for Adapting Existing Models
}

\author{
Anne Mikelonis, Timothy Boe, Worth Calfee and Sang Don Lee \\ U.S. Environmental Protection Agency, National Homeland Security Research Center, Durham, North Carolina.
}

\begin{abstract}
Wide area urban contamination events, such as after a terrorist attack or other chemical, biological or radiological disaster, pose a logistical challenge for response and remediation. The extent of contamination, both on the surface and subsurface, directly impacts the costs related to characterization sampling, decontamination, and clearance sampling (e.g. personnel, consumables and waste management). Modeling tools that can predict the location and magnitude of contamination may allow for a more efficient allocation of key resources since wide area incidents may be very costly, and take an extended amount of time, to remediate. This paper identifies 27 existing water models that are able to simulate hydraulic, hydrologic and water quality processes and discusses the necessary adjustments to running the models during remediation activities. It also highlights how these features relate to the unique considerations encountered in the homeland security sector and discusses ongoing research needs.
\end{abstract}

\section{Introduction}

\subsection{The Need}

Events that distribute hazardous material over large expanses of land (wide area incidents) are unexpected, require coordination between a number of local, state and federal agencies, and involve many interrelated activities associated with sampling, decontamination, and waste management. Since the Amerithrax incident in 2001, where Bacillus anthracis spores sent through the mail resulted in five fatalities, considerable efforts have been made in the United States to develop capabilities for remediating biologically affected areas (Gorman 2012; Wood et al. 2015; Calfee and Wendling 2015; Silvestri et al. 2016; Rose and Rice 2014; Ryan et al. 2010). However, the most efficient path to effectively remediate a wide outdoor urban area, including underground systems, is not clear. Stormwater modeling tools have the potential to provide responders and other officials with valuable and actionable information related to an event. It would be useful to have models that could be rapidly deployed after the release of a chemical, biological or radiological (CBR) agent and which could provide answers to questions such as: How far has a contaminant spread? Where are areas that the contaminants accumulate? How much and where does the contamination remain on the streets after rain events? Where are the contaminants entering and migrating into receiving lakes and streams? Where and how much of the contamination is entering the sewers? The objective of this paper is to draw attention to some of the necessary con- siderations when adapting traditional water models to manage the consequences of a biological or radiological terrorist attack or other disasters. A brief overview of the United States homeland security related emergency response, existing software options, and research gaps is also provided.

\subsection{Agency Involvement}

Response to a CBR incident involves a complicated multi-agency approach. Understanding the role of the U.S. Environmental Protection Agency (USEPA) helps to understand how modeling tools might be developed and then implemented during a recovery effort. Under Homeland Security Presidential Directive 10 (HSPD-10), the U.S. Department of Homeland Security (DHS) is tasked to coordinate with other appropriate federal departments and agencies, to develop comprehensive plans which "provide for seamless, coordinated federal, state, local, and international responses to a biological attack" (The White House 2004). As part of these plans, USEPA, in a coordinated effort with DHS, is responsible for "developing strategies, guidelines and plans for decontamination of persons, equipment and facilities" to mitigate the risks of contamination following a biological weapons attack. For USEPA, the Bioterrorism Act, Presidential Directives and Executive Orders, and the National Response Framework are legislative drivers that dictate agency involvement. Under the DHS National Response Framework, USEPA is designated as the coordinating federal agency to prepare for, respond to, and recover from oil and hazardous materials incidents (U.S. Homeland Security 2016).

Mikelonis, Anne, Timothy Boe, Worth Calfee and Sang Don Lee. 2018. Urban Fate and Transport Modeling of Contaminants: The Unique Needs of Emergency Response and the Potential for Adapting Existing Models. Journal of Water Management Modeling 26:C447.

https://doi.org/10.14796/JWMM.C447 @ CHI 2018. www.chijournal.org ISSN 2292-6062. 
Depending on the event, elements of the Comprehensive Environmental Response, Compensation, and Liability Act (Superfund), CERCLA, the Emergency Planning and Community Right-to-Know Act (EPCRA), the Clean Water Act, the Safe Drinking Water Act, the Oil Pollution Act, the Clean Air Act, and the Resource Conservation and Recovery Act (RCRA) authorize USEPA to respond. Examples of USEPA's responsibilities include: supporting water systems in preparation for, and during recovery from, attacks and other disasters; cleaning up impacted buildings and outdoor areas; and developing a nationwide laboratory network with the capability to analyze CBR agents in environmental samples. Predictive models are one of many tools that the agency uses and develops to respond to wide area incidents.

It is important to recognize that many groups within USEPA may be involved in the remediation process and therefore various actors will have different interests in the capabilities and application of modeling tools. At the site level, the USEPA regional on-scene coordinator's (OSC) roles are to assess, monitor, and direct the response in coordination with incident command and technical working groups. Among many agency resources, USEPA's Consequence Management Advisory Division (CMAD) in the Office of Emergency Management, as well as the research developed at the National Homeland Security Research Center (NHSRC) in the Office of Research and Development (ORD), are both available to the OSCs. NHSRC currently maintains and updates several water distribution and waste management tools (USEPA 2013; 2014b; 2014c; 2017; Shang 2008). Additional modeling tools have been developed by ORD to support regulatory and other research objectives. When radiological contamination is involved the Office of Radiation and Indoor Air (ORIA) and the Radiological Emergency Response Team (RERT) is intimately involved.

\subsection{Consequence Management}

From a technical standpoint, a remediation effort includes three key components: sampling, decontamination and waste management. Sampling is conducted to identify how much and where contaminants are located. Geiger counters provide rapid indication of the presence and intensity of radioactive material, allowing for quick assessment of contamination. Biological sampling can be much more time consuming due to the need for precise collection techniques such as vacuuming and swabbing (Calfee et al. 2013; Tufts et al. 2014). This activity is further complicated because of the limited number of certified laboratories capable of analyzing biological agents. As such, the turnaround time of results may be slow during a wide area incident response. A hypothetical scenario of aerosolized Bacillus anthracis spores dispersed across a $5.2 \mathrm{~km}^{2}$ dense urban area found roughly 30 million samples would need to be taken to identify, at 95\% probability of detection, a $0.9 \mathrm{~m}^{2}$ sized hotspot in the outdoor, indoor or underground environment (Hayes 2016). This suggests that probability based sampling plans using existing methods would pose a substantial economic and logistical burden. Judgmental sampling plans, with current technologies, are one method that has been proposed to overcome this sampling challenge for some aspects of remediation. If stormwater models were refined to predict the boundaries of contaminant hotspots on roads and land cover under different weather conditions, the visualizations would provide planners and samplers with maps of the areas to more efficiently target sampling efforts. Analysis priority could also be assigned to samples that are more likely to contain high levels of the hazardous material.

Following site assessment, decontamination is likely to be performed to remove or mitigate the danger of the hazardous material. After the Fukushima Daiichi nuclear power plant incident, characterizations of water flow paths from existing hydrogeological maps were critical for assessing mobilization pathways for radionuclides and potential routes for recontamination. The observed transport was predominantly associated with radiocaesium soil particles which were mobilized during periods of high rainfall (Nakayama et al. 2015). Existing stormwater models could be leveraged to calculate necessary contact times of decontaminants in pipes and predict runoff pathways of spray based methods so that they do not affect clean areas downstream of the event. Treatment could also be modeled to predict the effectiveness of remediation alternatives.

Waste management is an ongoing part of the remediation process. Waste can be generated from personal protective gear, the liquid runoff of decontaminants, water used as an exposure mitigation technique (e.g. hosing down streets or dust suppression), water used to rinse responders, and solids removed from the site rather than undergoing remediation; all must be disposed. Estimates of liquid waste volumes from a wide area incident have been of the order of magnitude of billions of liters (Boe et al. 2013). Stormwater models may be useful for selecting staging locations that minimize the risk that runoff will contaminate clean zones. Water quality features in models may also prove useful in demonstrating if the disposal of liquid wastes into the stormwater system would be detrimental or not.

\subsection{Contaminants of Concern}

CBR agents are likely unfamiliar to most practitioners in charge of city stormwater and watershed models, but a wealth of information is available in the peer reviewed literature (Bartelt-Hunt et al. 2008; Garcia-Sanchez and Konoplev 2009; Greenberg et al. 2010; Sinclair et al. 2008). An introduction to biological (e.g. anthrax) and to radiological contamination in particulate form (assumed to be inert and not chemically changed during transport) will be the focus of this paper because of the environmental persistence of these forms of contamination. Chemical weapons such as blister and nerve agents are also of concern, but the modeling approach is expected to depend more heavily on the solubility, degradation reactions and partitioning properties that vary significantly between agents. The U.S. Department of Health and Human Services (HHS) and the U.S. Department of Agriculture (USDA) maintain a federal select agent program that identifies biological agents and toxins which have the potential to pose a 
severe threat to public, animal or plant health. The U.S. Centers for Disease Control and Prevention (CDC) places bioterrorism agents into categories A, B and C (Table 1).

Table 1 CDC bioterrorism agent categories by disease and causative agent.

\begin{tabular}{l} 
Bioterrorism agent \\
\hline Category A \\
Anthrax (Bacillus anthracis) \\
Botulism (Clostridium botulinum toxin) \\
Plague (Yersinia pestis) \\
Smallpox (variola major) \\
Tularemia (Francisella tularensis) \\
Viral hemorrhagic fevers \\
\hline Category B \\
Brucellosis (Brucella species) \\
Epsilon toxin of Clostridium perfringens \\
Food safety threats (e.g. Salmonella species, Escherichia coli 0157:H7, Shigella) \\
Glanders (Burkholderia mallei) \\
Melioidosis (Burkholderia pseudomallei) \\
Psittacosis (Chlamydia psittaci) \\
Q fever (Coxiella burnetii) \\
Ricin toxin from Ricinus communis (castor beans) \\
Staphylococcal enterotoxin B \\
Wyphus fever (Rickettsia prowazekii) \\
Catencephalitis
\end{tabular}

Category A agents, which pose the highest risk to national security, can be easily disseminated or transmitted from person to person, result in high mortality rates, require special preparedness actions, and have the potential to cause public panic and disruption. Category B agents are moderately easy to disseminate, result in moderate morbidity rates and low mortality rates, but require the enhancement of diagnostic and surveillance capability. Category $C$ agents are of emerging concern because of their availability, ease of production for mass dissemination, and potential for a major health impact. Previous research has surveyed the environmental persistence of category A and category $B$ agents and found a wide range of viability depending on matrix and environmental conditions (USEPA 2014a). While all bioterrorism agents are cause for concern, Bacillus anthracis, the causative agent of anthrax, has garnered substantial research attention because it persists for years, it is easy to spread, and inhalational anthrax is particularly deadly (D'Amelio et al. 2015). Generally, organisms capable of forming spores have a prolonged environmental persistence and are more resistant to decontamination, making them a good conservative test organism for other efforts as well (McDonnell and Russell 1999).
Wide area radiological contamination, whether from the detonation of a radiological dispersal device, improvised nuclear device (aka a dirty bomb), or an accidental release from a nuclear power plant, is a concern (Kaminski et al. 2016). The primary radionuclides of concern are ${ }^{137} \mathrm{Cs}$ and ${ }^{90} \mathrm{Sr}$ which have long halflives and known adverse effects on human health. The area of contamination will vary significantly depending upon the type of detonation. A dirty bomb is likely to be limited to the scale of several city blocks (USEPA 2015). Modeling a wide area radiological event will require a model capable of calculating air dispersion behaviour, and specifically incorporating infrastructure geometry, which has been shown to affect deposition patterns (Jonsson et al. 2013). Stormwater is also considered a major transport mechanism of radiological contamination. After the Fukushima nuclear power plant disaster in 2011 , surface runoff contained ${ }^{137} \mathrm{CS}$ (USEPA 2015). In urban areas outside of Chernobyl, radiological street contamination decreased over time due to natural weathering. However, in some areas the contamination remained on streets for up to $7 \mathrm{y}$ (Andersson et al. 2002). It is expected that large open permeable areas will serve as sinks of radiological contamination. Parks in urban areas have demonstrated this effect (Avery 1996). The migration rate of radionuclides in soil is slow (centimetres over decades) therefore groundwater contamination is less of a concern than runoff processes (Ohta et al. 2012). A number of radiological fate and transport models were developed post Chernobyl and have been reviewed extensively by others (Gallego 2006; Monte et al. 2005; Monte et al. 2004). The partitioning coefficients commonly used in models, such as the European Commission's model based computerized system for management support to identify optimal remedial strategies for restoring radionuclide contaminated aquatic ecosystems (MOIRA), may be a useful resource for obtaining the washoff and partitioning coefficients needed by the standard storm and watershed models that are used by municipalities on a more routine basis.

\section{Models}

\subsection{Model Review}

Over the years, many modeling tools have been developed to serve the hydraulic and water quality needs of municipal systems. Projects have included, but are not limited to, network design, system management, low impact development, flood control, and watershed protection. For this work, the tools considered had capabilities to simulate hydrology, hydraulics, and the fate and transport of pollutants in urban environments, including overland flow and pipe networks in stormwater systems, because these elements were identified as necessary for answering the common questions posed during remediation. From internet searches and peer reviewed literature, 58 models or modeling software packages were identified as currently being used by municipal governments and containing some of these elements. They ranged in complexity from spreadsheets to sophisticated software. Many of the models excelled at only one or two of the computational 
aspects and therefore were not investigated further (Table 2). Some of these models may still have the potential for adoption, but would likely require integration into other software in order to produce risk maps of contaminants. After the initial screening, 27 models or software packages were found to include hydraulic, hydrologic and water quality capabilities and were included in a more detailed review (Table 3).

Table 2 Models and software that were rejected during initial screening, by primary reason.

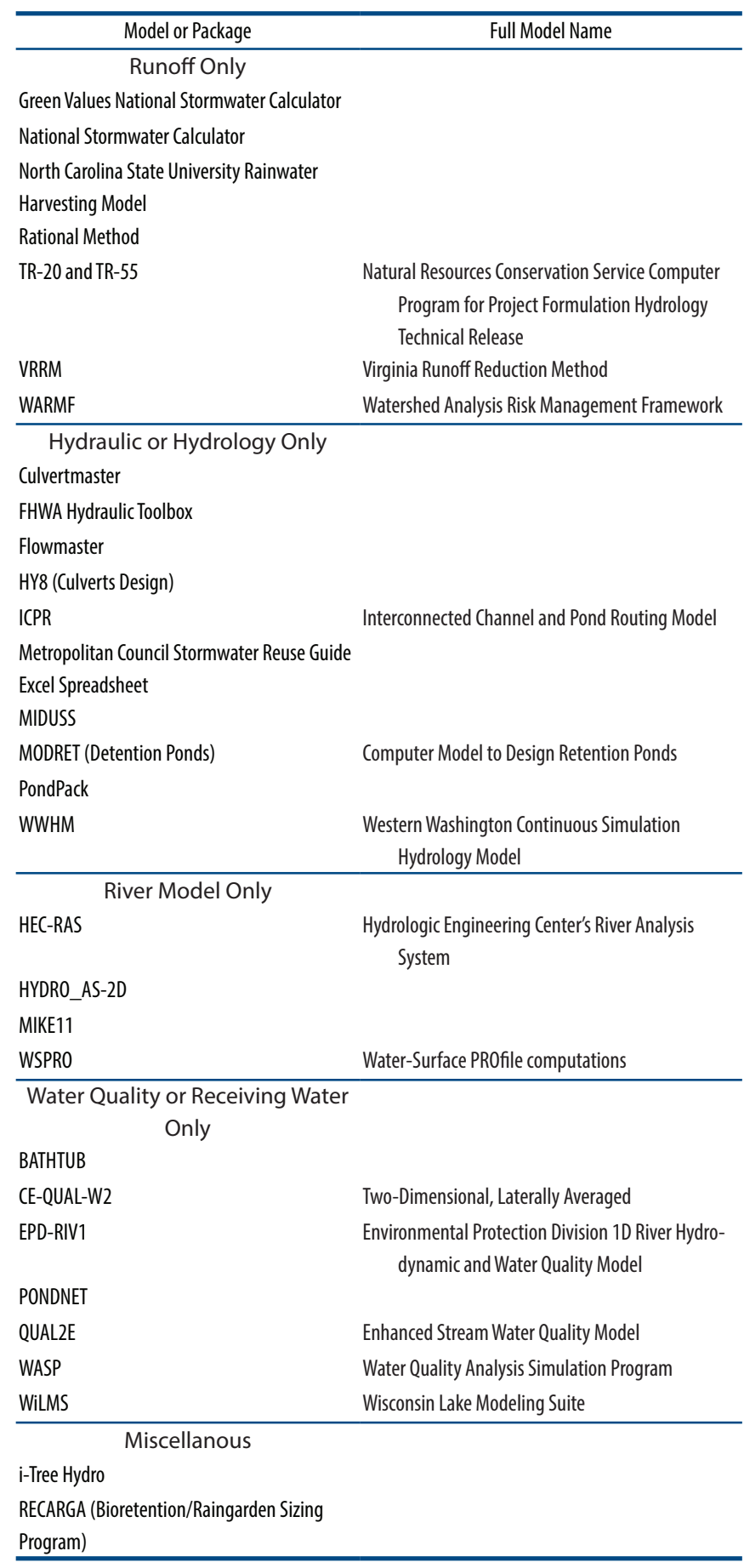

Table 3 Models and software selected for detailed review; the organization sponsoring the model or software development is given in parentheses.

\begin{tabular}{|c|c|}
\hline Model or Software & Full Model Name \\
\hline Watershed Mode & \\
\hline BASINS & $\begin{array}{l}\text { Better Assessment Science Integrating Point and } \\
\text { Nonpoint Sources }\end{array}$ \\
\hline
\end{tabular}

GSSHA (U.S. Army Corps of Engineers, USACE) Gridded Surface Subsurface Hydrologic Analysis GWLF (Cornell University) Generalized Watershed Loading Function

HEC-HMS (U.S. Army Corps of Engineers, USACE) Hydrologic Engineering Center-Hydrologic Modeling System

HSPF (Aqua Terra, U.S. Geological Survey, USGS, Hydrological Simulation Program - Fortran U.S. Environmental Protection Agency, USEPA)

LSPC (U.S. Environmental Protection Agency, Loading Simulation Program C USEPA)

MapShed (Penn State Institutes of Energy and the Environment)

QHM (SSG)

SWAT (U.S. Department of Agriculture, USDA) Soil and Water Assessment Tool

WARMF (Systech) Watershed Analysis Risk Management Framework

Sewer and Stormwater Modeling Software

InfoWorks ICM (Innovyze)

MikeUrban (DHI)

P8 (Walker and Walker)

SHSAM (Barr Engineering)

WinSLAMM (PV and Associates, LLC) SWMM Family

InfoSWMM (Innovyze)

PCSWMM (CHI)

SWMM (U.S. Environmental Protection Agency, USEPA) XPSWMM (XP Solutions)

\begin{tabular}{l} 
Sewer Models \\
CivilStorm (Bentley) \\
HydroCAD (HydroCAD Software Solutions LLC) \\
\hline \multicolumn{1}{c}{ Support Tools } \\
MIDS Calculator (Minnesota Pollution Control Minimal Impact Design Standards \\
Agency, MPCA) \\
SELDM (U.S. Geological Survey, USGS/ Federal Stochastic Empirical Loading and Dilution Model \\
Highway Administration, FHA) \\
SELECT (Water and Environment Research \\
Foundation, WERF) \\
STEPL (U.S. Environmental Protection Agency, Spreadsheet Tool for Estimating Pollutant Loads \\
USEPA) \\
SUSTAIN (U.S. Environmental Protection Agency, System for Urban Stormwater Treatment and \\
USEPA) \\
\hline
\end{tabular}

The detailed review compiled the following key information: code developer, hardware computing requirements, code language, original application (e.g. urban, rural), public or proprietary, cost, physical or empirical basis, core mathematical 
methods (e.g. for flow routing and water quality), required and optional input data, output options, representation of uncertainty, prevalence, and ease of use for public utilities. The information was collected from descriptions and documentation on the model's official website, the model manuals, factsheets listed on the model website, literature search based on the model's name and case studies of the model applications to real study sites obtained from internet searches. This extensive detailed information will be made available as a future USEPA technical report.

Four groupings of modeling software which were reviewed in detail and that contained all the desired computational aspects emerged, as shown in Table 3. One set of models (HydroCAD, InfoWorks ICM, and CivilStorm) had a core focus on pipe flow within sewers, but some organizations offer expansion products. Many of the models that solve the fundamental hydrologic, hydraulic and water quality equations were classified as watershed models. While these contain advanced capabilities for pollutant transport, they are not commonly linked to detailed sewer networks. Some of the models are better described as decision support tools. For example, SUSTAIN uses portions of both SWMM and HPSF code and provides users with a framework to evaluate stormwater best management practices. Models with the capability to simulate water quality, pipe networks and 2D overland flow (InfoWorks ICM, MikeUrban, PCSWMM, InfoSWMM and XPSWMM) form the suite of tools with the most robust capabilities for remediation after a terrorist attack. Existing models in other formats are still useful in terms of data and specialized modeling compartments. They will need to be combined with these other tools to answer all of the questions that are useful during response efforts.

\section{Unique Modeling Considerations}

During a response, leveraging a city's existing sewer network and watershed models could save resources and more rapidly inform decision making. Ideally, pre-existing models on a platform that is widely used and accepted at a local level will be utilized. However, during the model review it was found that no one model is readily usable for the types of applications conceived as beneficial during consequence management of a wide area response. Recognition of potential hurdles can help prepare for an incident. This section outlines considerations related to model alterations. It also highlights logistical considerations that municipalities should anticipate and start planning for now.

Modeling efforts can encounter difficulties during remediation. These include, but are not limited to, aspects related to repurposing an existing model, model ownership (e.g. the modeling was done entirely by outside consultants no longer on retainer), or the model has the wrong resolution or dimensionality for the current scenario. Often models are developed to address specific questions encountered by a municipality, and this can lead to certain challenges if that model is to be used for a wide area CBR incident. Models may be highly detailed for a small portion of an urban area, or represent a large area with lower resolution. Modeling too small an area will miss the impact outside the model scope, while modeling too large an area results in long runtimes for high resolution or missed details if using a coarse grid.

Detailed surface remediation will require modifications to existing models. Models will need to be converted from a 1D sewer network to a 2D overland flow model. This will require digital elevation data, a shape file of the building footprints, and the locations of sewer inlets. In order to achieve the desired spatial resolution of pollutant surface concentrations, subcatchments will need to be redefined from their original sewer drainage areas to much smaller areas. This is particularly necessary in SWMM because pollution can only be assigned to a particular land use within a subcatchment. By creating smaller subcatchments that match the size of the 2D mesh, it is possible to match contaminant location more precisely to the source of the release and any air plume deposition modeling results. In addition to adjusting subcatchment size, the coefficients for processes such as infiltration and washoff will need to be updated to an appropriate value for the agent released during the incident.

Many municipalities use outside consultants for their modeling needs and, internally, infrastructure information is maintained by different departments. City planners could map out key data contacts and data sources now as part of their emergency planning practices. Even if model conversions are not a top priority for local routine operations, having a sense of what information would be missing, the formats it needs to be in, and where in the government structure the information is located are very important to know ahead of an incident.

Out-of-the-normal collaborations between different levels of government and scientific expertise will also form during the response (e.g. technical support working groups). For example, after the incident air pollution models may produce predicted plumes of contamination. Water modelers will need to coordinate with air modelers to use these outputs as initial concentration estimates. These surface deposition concentrations will serve as input for washoff predictions from rain events and updated deposition plumes should be used if the weather events impact the air model predictions. The modeler also needs to plan on integrating sampled concentration results, as they are returned from the laboratory, as validation points and to be prepared to assist decision makers in identifying locations where contaminated runoff will not reach sensitive equipment or where waste can be stored without exacerbating contamination.

The time available to prepare and run the model during a response is likely to be very compressed compared to typical modeling projects. Normal sources of climate data at the needed temporal and spatial resolutions may not be available for the initial model runs. Plans should be made ahead of emergency events for the sequence and data processing of forecasted weather data, rainfall data from federal government data sets, and local rain gauges. Computer scripts can be developed ahead of events to retrieve and format the data for use in the models. Also, supercomputing power should be secured ahead of time from federal 
agencies, universities, and other organizations for instances that require high resolution $2 \mathrm{D}$ modelling over a wide area. This level of detail will greatly increase computational times so at the start of each modelling effort, it should be discussed in which areas coarser resolution would suffice. Modelers should be prepared to rerun simulations multiple times as more data become available and communicate with decision makers the uncertainty in the results at various stages of the response.

It is also important to acknowledge that, historically, water quality modeling predictions have been subject to greater inaccuracies than hydraulic modeling predictions. Also, measuring the water quality of overland flow before it reaches receiving waters is very rare. Laboratory and field scale validation exercises need to be performed with surrogates for CBR agents in order to better understand the uncertainty associated with predicting their behaviour and transport using stormwater models. A better understanding in this area has further benefits for the creation of stormwater quality regulation for more routine contamination as well.

\section{Conclusions}

Stormwater models can be an asset when responding to a terrorist attack or some other disaster that affects a wide urban area, but coordinated efforts are needed in advance in order to adjust and prepare them for implementation. Many different software options for simulating hydrologic, hydraulic and water quality processes are available and in use throughout the United States, but only a handful integrate 2D overland flow, pipe network and water quality algorithms into one package. They must be modified and validated through field and laboratory studies to incorporate CBR transport properties and provide case studies for modelers who will respond to an incident. Validating models for highly hazardous materials is challenging. It requires ongoing efforts to carefully design physical laboratory models and to select representative surrogates safe for environmental release. Sensor advancements for measuring the depth of very shallow water in streets is also needed. Local government assessments of their current portfolio of data and models with a discussion of where and how these could be used during a response will aid in better understanding current capability gaps and in enhanced response. The results of these efforts hold the potential to provide enhanced mapping functionalities that will aid in the sampling, decontamination and waste management at a site following a wide area CBR incident.

\section{References}

Andersson, Kasper Grann, Jørn Roed and C. L. Fogh. 2002. “Weathering of Radiocaesium Contamination on Urban Streets, Walls and Roofs." Journal of Environmental Radioactivity 62 (1): 49-60.

Avery, Simon V. 1996. “Fate of Caesium in the Environment: Distribution Between the Abiotic and Biotic Components of
Aquatic and Terrestrial Ecosystems." Journal of Environmental Radioactivity 30 (2): 139-71.

Bartelt-Hunt, Shannon L., Detlef R. U. Knappe and Morton A. Barlaz. 2008. "A Review of Chemical Warfare Agent Simulants for the Study Of Environmental Behavior." Critical Reviews in Environmental Science and Technology 38 (2): 112-36.

Boe, Timothy, Paul Lemieux, Daniel Schultheisz, Tom Peake and Colin Hayes. 2013. "A Planning Tool for Estimating Waste Generated by a Radiological Incident and Subsequent Decontamination Efforts-13569." WM2013 Conference, February 24-28, 2013, Phoenix, Arizona USA. Tempe, AZ: WM Symposia. http://www.wmsym.org/archives/2013/papers/13569.pdf

Calfee, M. Worth, Laura J. Rose, Stephen Morse, Dino Mattorano, Matt Clayton, Abderrahmane Touati, Nicole Griffin-Gatchalian, Christina Slone and Neal McSweeney. 2013. “Comparative Evaluation of Vacuum-Based Surface Sampling Methods for Collection of Bacillus Spores." Journal of Microbiological Methods 95 (3): 389-96.

Calfee, M. W. and M. Wendling. 2015. "Inactivation of Burkholderia pseudomallei on Environmental Surfaces Using SprayApplied, Common Liquid Disinfectants." Letters in Applied Microbiology 61 (5): 418-22.

D’Amelio, Enrico, Bernardina Gentile, Florigio Lista and Raffaele D'Amelio. 2015. "Historical Evolution of Human Anthrax from Occupational Disease to Potentially Global Threat as Bioweapon." Environment International 85:133-46.

Gallego, Eduardo. 2006. “MUD: A Model to Investigate the Migration of $137 \mathrm{Cs}$ in the Urban Environment and Drainage and Sewage Treatment Systems." Journal of Environmental Radioactivity 85 (2): 247-64.

Garcia-Sanchez, L. and A. V. Konoplev. 2009. "Watershed Wash-Off of Atmospherically Deposited Radionuclides: A Review Of Normalized Entrainment Coefficients." Journal of Environmental Radioactivity 100 (9): 774-8.

Gorman, Chad. 2012. Wide Area Recovery and Resiliency Program (WARRP) Interim Clearance Strategy for Environments Contaminated with Hazardous Chemicals. Washington D.C.: U.S. Environmental Protection Agency. https://www.hsdl.org/?view\&did=762963

Greenberg, David L., Joseph D. Busch, Paul Keim and David M. Wagner. 2010. "Identifying Experimental Surrogates for Bacillus anthracis Spores: A Review." Investigative Genetics 1 (1): 4.

Hayes, Colin. 2016. “The Application of Biological Agent Sampling Methods to a Wide-Area Incident." In Podium Presentation 11/3/2016, EPA International Decontamination Research and Development Conference, Durham, NC. Washington D.C.: U.S. Environmental Protection Agency.

Jonsson, Lage, Agneta H. Plamboeck, Erik Johansson and Mattias Waldenvik. 2013. “Various Consequences Regarding 
Hypothetical Dispersion of Airborne Radioactivity in a City Center." Journal of Environmental Radioactivity 116:99-113.

Kaminski, Michael D., Sang Don Le, and Matthew Magnuson. 2016. "Wide-Area Decontamination in an Urban Environment After Radiological Dispersion: A Review and Perspectives." Journal of Hazardous Materials 305:67-86.

McDonnell, Gerald and A. Denver Russell. 1999. "Antiseptics and Disinfectants: Activity, Action, and Resistance." Clinical Microbiology Reviews 12 (1): 147-79.

Monte, Luigi, Patrick Boyer, John E. Brittain, Lars Håkanson, Samuel Lepicard and Jim T. Smith. 2005. "Review and Assessment of Models for Predicting the Migration of Radionuclides Through Rivers." Journal of Environmental Radioactivity 79 (3): 273-96.

Monte, Luigi, John E. Brittain, Lars Håkanson, Jim T. Smith and Marcel van der Perk. 2004. "Review and Assessment of Models for Predicting the Migration of Radionuclides from Catchments." Journal of Environmental Radioactivity 75 (1): 83-103.

Nakayama, Shinichi, Keiichi Kawase, Kazuki lijima, Kaname Miyahara, Susan Hardie, Ian McKinley, Liza Klein and Shoko Yashio. 2015. Remediation of Contaminated Areas in the Aftermath of the Accident at the Fukushima Daiichi Nuclear Power Station. Overview, Analysis and Lessons Learned. Part 1: A Report on the "Decontamination Pilot Project". Japan Atomic Energy Agency.

http://dx.doi.org/10.11484/jaea-review-2014-051

Ohta, Tomoko, Yasunori Mahara, Takumi Kubota, Satoshi Fukutani, Keiko Fujiwara, Koichi Takamiya, Hisao Yoshinaga, Hiroyuki Mizuochi and Toshifumi Igarashi. 2012. “Prediction of Groundwater Contamination with 137 Cs and 131 I from the Fukushima Nuclear Accident in the Kanto district." Journal of Environmental Radioactivity 111:38-41.

Rose, L. J. and E. W. Rice. 2014. "Inactivation of Bacterial Biothreat Agents in Water: A Review." Journal of Water and Health 12 (4): 618-33.

Ryan, Shawn, Worth Calfee, Joseph Wood, Brian Attwood and Frank Schaefer. 2010. “Research to Support the Decontamination of Surfaces and Buildings Contaminated with Biothreat Agents." In Disinfection, Sterilization, and Antisepsis: Principles, Practices, Current Issues, New Research, and New Technologies, edited by William Anthony Rutala. Arlington, VA: APIC (Association for Professionals in Infection Control and Epidemiology).

Shang, F., J. G. Uber and L. Rossman. 2008. EPANET Multi-Species Extension Sofware and User's Manual. Washington, DC: U.S. Environmental Protection Agency.
Silvestri, Erin E., Sarah D. Perkins, Eugene W. Rice, Harry Stone and Frank W. Schaefer III. 2016. "Review of Processing and Analytical Methods for Francisella tularensis in Soil and Water." Annals of Microbiology 66 (1): 77-89.

Sinclair, Ryan, Stephanie A. Boone, David Greenberg, Paul Keim and Charles P. Gerba. 2008. "Persistence of Category A Select Agents in the Environment." Applied and Environmental Microbiology 74 (3): 555-63.

The White House. 2004. Homeland Security Presidential Directive 10 [HSPD-10]: Biodefense for the 21st Century. Washington, DC: The White House.

Tufts, Jenia A. M., Kathryn M. Meyer, Michael Worth Calfee and Sang Don Lee. 2014. “Composite Sampling of a Bacillus anthracis Surrogate with Cellulose Sponge Surface Samplers from a Nonporous Surface." PLOS One 9 (12): e114082.

USEPA. 2013. Threat Ensemble Vulnerability Assessment-Sensor Placement Optimization Tool (TEVA-SPOT) Graphical User Interface. Washington, D.C.: U.S. Environmental Protection Agency. Report Number EPA/600/R-13/014.

USEPA. 2014a. Persistence of Categories A and B Select Agents in Environmental Matrices. Washington, DC: U.S. Environmental Protection Agency Office of Research and Development. EPA/600/S-15/218

USEPA. 2014b. Waste Estimation Support Tool and User Guide. Washington, DC: United States Environmental Protection Agency. Report Number EPA/600/B-14/235.

USEPA. 2014c. Water Security Toolkit User Manual: Version 1.3. Washington D.C.: U.S. Environmental Protection Agency. Report Number EPA/600/R-14/228.

USEPA. 2015. Particle Transport of Radionuclides Following a Radiological Incident. Washington, DC: U.S. Environmental Protection Agency. EPA/600/R-15/113.

USEPA. 2017. EPA's Incident Waste Management Planning and Response Tool. Washington D.C.: US Environmental Protection Agency. Report Number EPA/600/S-17/184.

U.S. Homeland Security. 2016. National Response Framework. edited by US Department of Homeland Security.

Wood, Joseph P., Mathew J. Clayton, Timothy McArthur, Shannon D. Serre, Leroy Mickelsen and Abderrahmane Touati. 2015. "Capture of Methyl Bromide Emissions with Activated Carbon Following the Fumigation of a Small Building Contaminated with a Bacillus anthracis Spore Simulant." Journal of the Air \& Waste Management Association 65 (2): 145-53. 